\title{
O planejamento pastoral à luz do Documento de Aparecida
}

\author{
Prof. Dr. Côn. Sérgio Conrado
}

\section{RESUMO}

O Documento de Aparecida conclama a Igreja à conversão pastoral e resgata o Planejamento Pastoral como um autêntico instrumento para evangelizar hoje.

Palavras-chave: Doc. de Aparecida, Igreja, conversão pastoral, planejamento.

\begin{abstract}
Aparecida's Document shouts Church to pastoral conversion and ransoms pastoral planning as authentic instrument to evangelize today.

Key-words: Aparecida's Document, Church, pastoral conversion, planning.
\end{abstract}

\section{INTRODUÇÃO}

A V Conferência Geral do Episcopado Latino Americano e do Caribe afirma no Documento de Aparecida: "A Igreja é chamada a repensar profundamente e a relançar com fidelidade e audácia sua missão nas novas circunstâncias latino-americanas e mundiais"1. Pois bem, trata-se de uma tarefa que diz respeito a todos os fiéis, chamados em virtude do seu Batismo, a serem discípulos missionários de Jesus Cristo: "De modo especial o

1 DA,n.11 
laicato, devidamente formado, deve atuar como verdadeiro sujeito eclesial"2. Claro que para desempenhar essa missão evangelizadora é preciso que cada um tenha uma profunda vivência da fé, fruto de uma experiência pessoal de encontro com a pessoa de Jesus Cristo. Essa conversão pessoal dá a cada batizado, co-responsável pela ação da Igreja, a possibilidade de se desenvolver em plenitude a existência humana "em sua dimensão pessoal, familiar, social e cultural"3. Isso significa que, a partir da conversão pessoal, a ação pastoral correspondente também mudará.

É muito significativo que o Documento de Aparecida, como nenhum outro até agora, tenha colocado o dedo na ferida da pastoral, pois ao falar da conversão pastoral e renovação das comunidades, assim vigorosamente se expressa: "Esta firme decisão missionária deve impregnar todas as estruturas eclesiais e todos os planos pastorais de dioceses, paróquias, comunidades religiosas, movimentos... Nenhuma comunidade deve isentar-se de entrar decididamente, com todas as forças, nos processos constantes de renovação missionária e de abandonar as ultrapassadas estruturas que já não favoreçam a transmissão da fé"4.

Aí está, pois, o grande alerta da Conferência para os agentes de pastoral, sejam sacerdotes, religiosos, religiosas e leigos. Ninguém pode, por desculpa alguma, ficar fora desse enfoque dado especificamente à pastoral. Normalmente os documentos do Magistério não entram em particularidades; apresentam princípios, diretrizes. Aqui, não! Com todas as letras, o Documento de Aparecida incita a todos a virar a mesa. E ainda acrescenta:"A conversão pastoral de nossas comunidades exige que se vá além de uma pastoral de mera conservação para uma pastoral decididamente missionária para que o Evangelho possa continuar a introduzir-se na história de cada comunidade, de cada pastoral, de cada diocese ${ }^{5}$.

Após esse contundente apelo, os bispos participantes da $V$ Conferência mostram algumas pistas para a realização dessa conversão pastoral e dentre elas destaca-se o planejamento pastoral: "O projeto pastoral da diocese, caminho de pastoral orgânica, deve ser resposta consciente e eficaz para

\footnotetext{
${ }^{2}$ DA, n. 497

${ }^{3}$ DI 4

${ }^{4}$ DA, n. 365

${ }^{5}$ Cf.NMI 20
} 
atender às exigências do mundo de hoje com indicações programáticas concretas, objetivos e métodos de trabalho, formação e valorização dos agentes e a procura dos meios necessários que permitam que o anúncio de Cristo chegue às pessoas, modele as comunidades e incida profundamente na sociedade e na cultura mediante o testemunho dos valores evangélicos" ${ }^{\text {. }}$ O planejamento pastoral, portanto, retoma o seu valor imprescindível, como mediação para que toda essa transformação pastoral preconizada pela $\mathrm{V}$ Conferência possa se tornar realidade.

\section{PASTORAL: AÇÃO DIVINO-HUMANA}

Não há dúvida que a palavra pastoral no seu uso normal está caracterizada pela ambigüidade e falta de precisão, de tal maneira que se tornou complexa e confusa. Tudo ou quase tudo que se faz na Igreja é chamado de pastoral. E o que é pior: quase todos se acham instintivamente capacitados para tal. Basta muitas vezes, ter boa vontade. Nestes últimos duzentos anos, o significado de pastoral tem ampliado o seu raio de ação, de tal forma que, em primeiro se refere ao trabalho dos pastores, depois às tarefas intra-eclesiais e, por último, ao diálogo com o mundo ${ }^{7}$.

a) O Antigo Testamento mostra como a realidade do pastoreio está profundamente arraigado na cultura judaica e a figura do pastor se manifesta numa dupla função: chefe e companheiro ${ }^{8}$. O nome de pastor que é atribuído a Deus por Israel, mais que definição, serve para ilustrar a história de Israel a partir do amor que Deus Ihe manifestou. A ação de tirar o povo da escravidão do Egito e sua condução para o deserto é compreendida a partir da imagem do rebanho e das ovelhas ${ }^{9}$. Essa relação continua como exemplifica o profeta Isaías mostrando que Deus recolhe as ovelhas em seus braços ${ }^{10}$. Esta relação de Deus com o seu povo, como o pastor com suas ovelhas, ilumina o passado, garante o presente

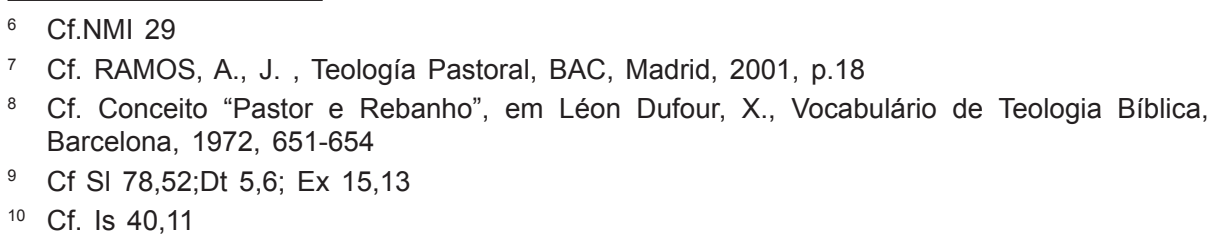


e prepara o futuro. O nome de pastor também é dado para os servidores de Deus que estão à frente do seu povo. Percebemos como Deus pastoreia o seu povo através de pastores escolhidos por ele para realizarem a sua tarefa. Moisés é o grande pastor do povo de Israel e depois dele Josué ${ }^{11}$ e mais tarde Davi ${ }^{12}$. A ação de pastorear tanto naquele tempo como hoje, se mede pela fidelidade. É por isso que na Sagrada Escritura, sempre se fala dos bons e dos maus pastores ${ }^{13}$. E a restauração do povo está unida ao "eu lhes darei pastores segundo o meu coração"14.

Podemos pois, dizer que a ação salvadora de Deus em relação a seu povo era apresentada a Israel em termos pastorais e esta ação se desenvolveu através de mediações humanas nem sempre fiéis como deveriam. E como a fidelidade de Deus supera a resposta humana, o seu pastoreio exige uma novidade no comportamento de seus pastores e que expresse na radicalidade a ação de Deus. Isto nos mostra como a ação divina e ação humana caminham juntas na pastoral e esta exigência está presente nos tempos messiânicos.

b) O Novo Testamento apresenta o Cristo na sua história e missão a partir do contexto religioso-cultural do seu povo, portanto, apresentando sua obra em termos pastoris. Os textos do AT a que fizemos menção são como marcos de referência para compreender a autoconsciência de Jesus e para falar de sua tarefa como a do pastor esperado ${ }^{15}$.

Três afirmações básicas caracterizam como Cristo assume a função de pastor. - A situação em que o povo se encontra é como a de um rebanho sem pastor $^{16}$. Esta situação do povo move a compaixão de Jesus e ele reúne as ovelhas dispersas ${ }^{17}$. - O próprio Cristo se apresenta como o bom pastor anunciado pelos profetas e a grande novidade é que este pastor veio

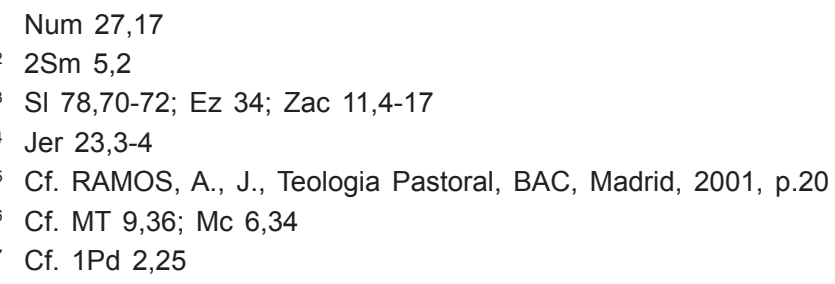


não só para as ovelhas de Israel, mas para todas as outras, mostrando o universalismo de sua ação redentora ${ }^{18}$.

- Assim como no AT, Jesus também elegeu e chamou pastores ${ }^{19}$ para que continuassem sua missão e com eles permaneceu de modo ressuscitado, tornando-se o príncipe dos pastores ${ }^{20}$. Essa convocação permanece sempre, uma vez que, pelo Batismo, cada um se torna participante do múnus profético, sacerdotal e real de Jesus Cristo.

Em resumo, podemos afirmar que uma das chaves da autoconsciência de Jesus está na missão de pastor anunciado e esperado pelo Antigo Testamento cuja tarefa é a da fidelidade ao Pai para tornar possível sua obra, para ser um verdadeiro mediador. Por isso, a ação de Jesus foi chamada de ação pastoral e a ação posterior de sua Igreja foi identificada pelo mesmo nome, da mesma maneira que foram chamados de pastores aqueles que a dirigem.

Daí a importância de colocar lado a lado a ação de Jesus e a ação da Igreja. A fidelidade e a identificação a Jesus Cristo são a identidade suprema da Igreja. A insistência da $V$ Conferência na conversão pastoral se baseia exatamente nessa radicalidade da escolha que Jesus fez dela como mediadora da salvação. E quando no seu ser e no seu agir esta escolha divina e missão não se manifestam claramente, é chegada a hora de conversão, de mudança, de criatividade.

O Planejamento pastoral vai nos mostrar que essa radicalidade da missão "não se trata só de estratégias para procurar êxitos pastorais, mas da fidelidade na imitação do Mestre, sempre próximo, acessível, disponível a todos, desejoso de comunicar vida em cada região da terra"21. Diante do exposto, a reflexão sobre o planejamento pastoral se torna necessária, pois se trata de um instrumento de ajuda para que ação divina, coadjuvada pela ação humana, faça com que o processo de salvação atinja, cada vez mais, pessoas, grupos, culturas, todos os povos.

\footnotetext{
${ }^{18}$ Cf. Jo 10,16

${ }^{19}$ Cf. Mc 3,1-19

${ }^{20}$ Cf $1 \mathrm{Pd} 5,4$

${ }^{21}$ DA, n. 372
} 


\section{PLANEJAMENTO PASTORAL: INSTRUMENTO PARA A EVANGELIZAÇÃO}

Não se pode pensar em um planejamento pastoral fora da realidade eclesial, isto é, no contexto em que a própria Igreja está inserida com o seu ser e sua ação. Sempre nos debatemos com diversos tipos de pastoral que entram em conflito e atrasam o desenvolver da evangelização. É interessante relembrar o que Pierre André Liégé (1921-1979), professor de teologia pastoral no Instituto Católico de Paris, escreveu sobre a pastoral e os perigos que a ameaçam.

Antes de mais nada, Liégé reconhece a presença de uma pastoral selvagem na qual triunfam o espontaneísmo e a ausência total de critérios de reflexão e de avaliação.

No entanto, com a utilização desesperada das ciências humanas, pode-se ter uma pastoral tecnocrática, na qual se constata um excesso de organização e proliferação de burocracia.

Encontra-se também, a pastoral abdicativa caracterizada por uma adaptação inoportuna e sem critérios aos desafios da cultura contemporânea.

A mais difusa porém, é a pastoral de conservação que repete e repropõe o que foi feito, justificada pelo mote de que sempre fizemos assim, atestando um imobilismo e uma ineficácia embolorada fora da realidade que permanentemente está em mudança ${ }^{22}$. Os Bispos em Aparecida, falando da fé, relembram esse tipo de pastoral subjacente: "Não resistiria aos embates do tempo uma fé católica reduzida a uma bagagem, a um elenco de algumas normas e de proibições a práticas de devoção fragmentada, a adesões seletivas e parciais das verdades da fé, a uma participação ocasional em alguns sacramentos, à repetição de princípios doutrinais, a moralismos brandos ou crispados que não convertem a vida dos batizados"23.Assim como a situação sócio-político-econômico-social e, agora também a religiosa, se tornaram muito flexíveis, seja para o positivo ou negativo, a ação eclesial com critérios teológicos e pastorais, precisa se reciclar para não trair a mensagem evangélica de um lado e responder pelo testemunho e anúncio

\footnotetext{
22 Cf. LIEGE, P., A., Position de Theologie pastorale, Le point théologique , Paris, 1971, 52ss.

${ }^{23}$ DA.n. 12
} 
de outro, às indagações e problemáticas das pessoas hoje. Já em 1996, o teólogo Joseph Ratzinger, hoje Papa Bento XVI, em uma conferência dizia: "Nossa maior ameaça é o medíocre pragmatismo da vida cotidiana da Igreja, no qual, aparentemente, tudo procede com normalidade, mas na verdade a fé vai se desgastando e se degenerando em mesquinhez"24.

É da própria Sagrada Escritura que recebemos lições e fundamentos de como a pastoral necessita ser orgânica e não uniformizada. Os Atos dos Apóstolos nos atestam que há na pastoral modelos construtivos ${ }^{25}$ e modelos conflituais diretamente ligados ao itinerário pastora ${ }^{26}$.

$O$ problema da inadequação entre os meios utilizados e os resultados obtidos continua sendo um desafio para a pastoral da Igreja. Ainda se trabalha muito na base da boa vontade e do amadorismo. Em algumas áreas, a Igreja já está bem como na informática, bastante na mídia, na utilização das ciências humanas, mas ainda falta um impulso maior. Quando Paulo VI escreveu a exortação apostólica Evangelii nuntiandi e falava da evangelização como tarefa da Igreja, sua preocupação maior não era com o conteúdo central da evangelização, mas sua eficácia: "Que eficácia tem em nossos dias a energia escondida da Boa Nova, capaz de sacudir profundamente a consciência do homem?"27. Para que o conteúdo seja eficaz, o Santo Padre pergunta sobre as mediações pastorais:"Até onde e como esta força evangélica pode transformar verdadeiramente o homem de hoje? Com que métodos deve-se proclamar o evangelho para que seu poder seja eficaz?"28. $\mathrm{E}$, posteriormente, quando se começou a falar de nova evangelização como programa pastoral para a Igreja, os novos métodos estão sempre presentes em qualquer aproximação do tema.

Pois bem, o planejamento pastoral se apresenta hoje, como um desses novos métodos, não tão novos, que podem tornar mais eficaz a ação da Igreja. Planejamento não se identifica com eficácia como tal e nem esgota a

24 RATZINGER, J., Situação atual da fé e da Teologia - Conferência pronunciada no Encontro de Presidentes de Comissões Episcopais da América Latina para a doutrina da fé, celebrado em Guadalajara, México, 1996. Publicado em L"Os servatore Romano, em $1^{\circ}$ de novembro de 1996.

25 Cf. At , 2-10

26 Cf. At $5,1-11 ; 6,1-7 ; 15,1-4$

27 EN 4

28 Idem 
novidade dos meios na evangelização, mas sim, está a seu serviço. Nesse tempo, pós Aparecida, a Igreja deve perguntar-se a cada momento de sua história pelas formas concretas de realizar a sua missão para que sejam eficazes.

a) Planejar significa situar em uma organização todos os elementos pastorais para se atingir os fins que a ação da Igreja se propõe ou então, "é o processo de tomar decisões sobre o trabalho a ser feito...Esse processo acompanha todo o trabalho e vai indicando caminhos o tempo inteiro"29. Por outro lado, plano é o registro por escrito das motivações, objetivos, diretrizes e atividades decididas para se atingir o objetivo final. Ainda, cronograma é a lista de ações a serem realizadas com prazo, agentes, destinatários ${ }^{30}$.

Muito se tem falado contra e a favor de planejamento e plano. Uns não podem nem ouvir falar a respeito, pois argumentam que plano encarcera o Espírito, faz perder a espontaneidade. Outros elogiam, mas na prática o ignoram. Na realidade, o que se esconde atrás dessas posturas é, certamente o medo do novo, sair de antigos hábitos de acomodação, insegurança diante dos procedimentos a serem tomados.

b) Portanto, eis algumas indicações fundamentais sobre as etapas de um processo de planejamento. Isto implica em sistematizar e colocar em relação os elementos de modo que nenhum atue por conta própria à margem do conjunto. Abranger a totalidade dos elementos pastorais: pessoas, ações, estruturas, meios, fins. Aliás, tudo o que compõe a ação pastoral tem de ser incluído em um programa. Elaboração intelectual é necessária antes da ação, pois é ela que determina e dirige. O planejamento busca a eficácia e deve contar com os recursos necessários e está inserido em uma situação determinada e a um projeto a ser realizado. Por isso é de fundamental importância, antes de qualquer programação pastoral, conhecer a situação existente e explicitar a situação que se quer atingir ${ }^{31}$.

\footnotetext{
${ }^{29}$ CNBB, É hora de mudança, São Paulo, Loyola, 1998, p.17

${ }^{30} \mathrm{Cf}$ idem

${ }^{31}$ Cf; HEPP, N., verbete Piano Pastorale, em Dizionario di Pastorale, Brescia, 1979, 568
} 
Daí termos:

- A análise crítica da situação. Consiste em avaliar a prática pastoral existente a partir do seu conhecimento que a identifica e a contextualiza. Quanto mais esse conhecimento for rigorosamente científico, melhor. Esse momento abrange a análise fenomenológica que é o conhecimento da realidade do mundo, da Igreja, das ações e o contexto em que isso tudo acontece (ver). A análise crítica corresponderia ao julgar, isto é, avaliar a situação analisada com criteriologia teológica e eclesial para que se perceba se a essência da Igreja corresponde à sua existência, se há um agir que procede claramente do ser. E por fim, nesse primeiro momento, a análise soteriológica, isto é, descobrir na situação analisada se está presente o plano divino da salvação. Na verdade, é verificar se Deus está se manifestando na história humana através do que a Igreja realiza.

- Essa análise bem feita, abrangente, com a participação de diferentes tipos de pessoas, profissionais, já nos mostra, de alguma forma, o que podemos fazer para ir de encontro ao apelo vigoroso do Documento de Aparecida ao nos falar da conversão pastoral ${ }^{32}$.

- Projeto da situação desejada. Surge a partir da insatisfação diante da prática pastoral analisada ou a insuficiência de ações pastorais para atingir os objetivos previstos. Sem esta insatisfação não necessitaríamos de projeção de uma nova situação e nem a busca de ações para atingi-la. A $\vee$ Conferência, na terceira parte do documento, insiste para que, em vista de uma renovação pastoral, nos sintamos insatisfeitos diante de novos rostos sofredores e que devem doer em nós: "pessoas que vivem nas ruas das grandes cidades; migrantes, enfermos, dependentes de drogas, detidos em prisões"33. Diante de uma situação que se quer atingir, os objetivos, tanto gerais como específicos são fundamentais, bem como os objetivos operativos que dão o passo da teoria para a prática, concretizam cada um dos objetivos específicos. $O$ projeto

${ }^{32}$ Cf.,DA, n.365

${ }^{33}$ DA, n. $407,411,417,422,427$. 
de uma situação nova e o seu desenrolar em objetivos deve ser assumido por todos os que irão participar de sua realização, de modo que ninguém fique à margem do processo de projeção para não ficar à margem do processo de programação. A melhor maneira de um plano ser assimilado é que tomem parte direta ou representativamente, no processo de sua formulação todos os implicados. Assim, os diferentes agentes se sentirão membros ativos do Povo de Deus, co-responsáveis pela missão da Igreja.

Nesse ponto, a $V$ Conferência dá algumas diretrizes para que, na elaboração de um plano de pastoral sejam levados em conta "muitos os que se dizem descontentes, não tanto com o conteúdo da doutrina da Igreja, mas com a forma como é apresentada" 34 . Trata-se de ampliar o raio de abrangência em termos de consulta para que o plano de pastoral seja o da diocese, forania, região episcopal e também o da paróquia reflita o maior número de pessoas e suas categorias. Assim diz o Documento de Aparecida: "...na elaboração de nossos planos queremos: a) Favorecer a formação de um laicato capaz de atuar como verdadeiro sujeito eclesial e competente interlocutor entre a Igreja e a sociedade, e entre a sociedade e a Igreja. b) Otimizar o uso dos meios de comunicação católicos, fazendo-os mais atuantes e eficazes,seja para a comunicação da fé, seja para o diálogo entre a Igreja e a sociedade. c) Atuar com os artistas, esportistas, profissionais da moda, jornalistas, comunicadores e apresentadores, assim como com os produtores de informação nos meios de comunicação, com os intelectuais, professores, líderes comunitários. d) Resgatar o papel do sacerdote como formador de opinião"35. Papel importante na elaboração de um plano de pastoral exercem a Universidade Católica, os Centros de Fé e Cultura, pois nesses campos se criam e se dinamizam grupos de diálogo entre a Igreja e os formadores de opinião e do diálogo entre fé e razão ${ }^{36}$. O processo de planejamento pastoral ganharia e muito se a sua abrangência extrapolasse os limites não só geográficos, mas também de

\footnotetext{
DA, n. 497

Idem

Cf. DA, n.498
} 
freqüência. Ao se pensar em projetar uma nova situação em vista de uma renovação e atualizar as respostas pastorais diante dos novos desafios, é fundamental que a Igreja se abra para ouvir o que os outros, que "estão fora", pensam da própria Igreja, o que dela desejam, precisam, o que podem oferecer. Sem essa abertura, e para isso é necessário mais tempo de elaboração, recursos humanos, financeiros, corre-se o risco de se elaborar um plano à imagem e semelhança da própria diocese, paróquia, congregação e, talvez depois, dar respostas a questões que não foram colocadas. Por isso, muitas vezes, a palavra e a ação da Igreja não provocam reação e muito menos retorno.

- Aprogramação. É a fase estratégica que faz passar de uma situação atual para uma situação desejada, por meio de uma renovação e organização da ação pastoral. É nesta fase que os objetivos se tornam tarefas e ações pastorais; marcam-se os prazos das realizações, determinam-se os lugares onde acontecerão as ações, pessoas responsáveis e os meios necessários para realizálas. É claro que, às vezes, as situações complexas da Igreja e de sua ação tornam essa programação um tanto difícil, mas por isso mesmo se torna urgente e necessária para a pastoral. Com isso, muitas vezes, não se programa nada. No entanto, seguindo esses passos apresentados, mesmo que com mais simplicidade, a ação pastoral nos diferentes ambientes, sobretudo nos mais difíceis, seria um pouco mais refletida e identificada.

- A avaliação. É uma ação contínua que acompanha o processo de execução do plano para verificar se estão sendo realizados os objetivos propostos para cada etapa ${ }^{37}$. O grande equívoco que se dá com esse seguimento é que para muitos, a avaliação só se faz no final do período de vigência do plano. Esse modo de pensar empobrece a avaliação e não se tem uma visão objetiva do plano na sua execução. Não se pode esquecer que a atividade pastoral é uma realidade viva e que durante a execução do plano pode receber variações e por outro lado, outras ações não programadas, devido à urgência, poderão ser acolhidas.

37 Cf. PAYÁ, M., O Planejamento Pastoral a serviço da Evangelização, São Paulo, Ave-Maria, 2005, p.134 


\section{CONCLUSÃO}

As novas circunstâncias latino-americanas e mundiais chamam a lgreja a repensar profundamente e a relançar com fidelidade e audácia a sua missão. Não foi outro, o objetivo da $V$ Conferência do CELAM realizada em Aparecida. Há um desejo e uma conclamação que perpassam todo o Documento de Aparecida para que a novidade do Evangelho seja confirmada, renovada, revitalizada e vivida com mais intensidade pelos cristãos e pelos que virão a ser. $O$ caminho é o encontro pessoal profundo com a pessoa de Jesus Cristo $^{38}$.

No entanto, o DA mostra como a Igreja se encontra bastante fragilizada nos seus métodos para atingir o objetivo previsto. Daí o apelo à conversão pastoral que não se trata apenas em mudar o modo de evangelizar, mas atingir o próprio ser e agir da Igreja, pois o "único mediador, Cristo, constituiu e incessantemente sustenta aqui na terra sua santa Igreja, comunidade de fé, esperança e caridade, como organismo visível pelo qual difunde a verdade e a graça a todos ${ }^{39 "}$.

A revitalização da Igreja deve ser feita por tantas mediações abrangendo as dimensões humanas e sobrenaturais. Uma dessas mediações é sem dúvida, o Planejamento Pastoral. Trata-se de um modo de trabalho e de vivência que todos nós, conscientemente ou não, utilizamos no nosso dia-a-dia. Deus, na sua infinita misericórdia e bondade, pensou em um plano de salvação enviando seu Filho Jesus que sem dúvida, também como nos atestam os Santos Evangelhos, utilizou um planejamento vivencial e pastoral. A sociedade moderna não vive mais sem um planejamento. $E$ por que na Igreja há uma certa prevenção contra essa palavra, de maneira especial quando plano ou planejamento se referem a ela, como se Igreja não precisasse se organizar, uma vez que é assistida pelo Espírito Santo?

Jesus Cristo ao instituir a sua Igreja, também traçou metas a serem atingidas por ela: "... vão e façam com que todos os povos se tornem meus discípulos, batizando-os em nome do Pai, e do Filho, e do Espírito Santo, e ensinando-os a observar tudo o que ordenei a vocês". ${ }^{40}$
Cf. DA, 11
Cf. LG 8
${ }^{40}$ Cf. MT 28, 19 
Vivemos uma realidade ímpar, na qual a tecnologia está avançadíssima, as ciências rompendo horizontes. A Igreja deve estar presente em tudo e em todos, mas para isso necessita de um buscar constante de meios para aperfeiçoar seus métodos de ensino e de aprofundamento na fé. Sem dúvida, o planejamento já está presente na Igreja, mas é preciso que seja encarado como uma necessidade para todos e não apenas para os coordenadores maiores ou responsáveis de primeira linha. Desde um conclave papal até um grupo que se reúne em uma casa para meditar a Sagrada Escritura, é preciso um planejamento para garantir o bom andamento das ações.

Planejamento é um instrumento para renovar a Igreja. Para tanto é preciso trabalhar para que o número de pessoas perceba que o valor e a necessidade do planejamento seja cada vez maior. Claro que o planejamento pastoral não visa apenas resultados, porque trata-se de um trabalho com pessoas para pessoas e, portanto, deve ser flexível e passível de mudanças.

A Igreja no Brasil tem desenvolvido a sua ação pastoral desde 1963, utilizando o planejamento como um instrumento de comunhão e de coresponsabilidade. Iniciou com o Plano de Emergência, em pleno Concílio Vaticano II, e até hoje busca uma verdadeira pastoral de conjunto através das Diretrizes Gerais da Ação Evangelizadora. E na complexidade contemporânea em que vivemos, evangelizar necessita de planejamento em qualquer contexto, mormente nas grandes cidades. Terminamos ainda ouvindo os Bispos em Aparecida: "Para que os habitantes dos centros urbanos e de suas periferias, cristãos ou não cristãos, possam encontrar em Cristo a plenitude de vida, sentimos a urgência de que os agentes de pastoral, enquanto discípulos missionários se esforcem para desenvolver: ...um plano de pastoral orgânico e articulado que se integre em projeto comum às paróquias, comunidades de vida consagrada, pequenas comunidades, movimentos e instituições...". ${ }^{41} Q u e$ o clamor da $V$ Conferência para uma conversão pastoral encontre eco no coração dos discípulos missionários de Jesus Cristo e o planejamento seja um dos instrumentos dessa realização.

Prof. Dr. Côn. Sérgio Conrado

Professor na Pontifícia Faculdade de Teologia N. Sr. da Assunção/SP.

41 DA,n.518 


\section{BIBLIOGRAFIA}

CELAM - Documento de Aparecida - Texto conclusivo da V Conferência Geral do Episcopado Latino-Americano e do Caribe. Brasília, São Paulo: CNBB, Paulinas, Paulus, 2007.

RAMOS, A.J., Teología Pastoral. Madrid: BAC, 2001.

DUFOUR, L.X., conceito Pastor e Rebanho, em Vocabulário de Teologia Bíblica. Barcelona: 1972, p. 651-654.

RATZINGER, J., Situação atual da fé e da teologia em: L'Osservatore Romano, (1 de novembro), 1996.

CNBB - É hora de mudança. São Paulo: Loyola, 1998.

HEPP, N. verbete Piano Pastorale em: Dizionario di Pastorale. Brescia: 1979, p.568.

PAYÁ, M., O Planejamento Pastoral a serviço da Evangelização. São Paulo: Ave-Maria, 2005.

VATICANO II. Lumen Gentium. Compêndio do Vaticano II. Petrópolis: Vozes, 2000. 